\title{
Dermatological Considerations in the Diagnosis and Treatment of Marginal Zone Lymphomas
}

This article was published in the following Dove Press journal:

Clinical, Cosmetic and Investigational Dermatology

\author{
Andrea Ronchi ${ }^{1}$ \\ Antonello Sica $\left(\mathbb{D}^{2}\right.$ \\ Paola Vitiello ${ }^{3}$ \\ Renato Franco (ID) \\ 'Pathology Unit, Department of Mental \\ and Physical Health and Preventive \\ Medicine, Università degli Studi della \\ Campania "Luigi Vanvitelli", Naples, \\ 80I38, Italy; ' Oncology and Haematology \\ Unit, Department of Precision Medicine, \\ University of Campania Luigi Vanvitelli, \\ Naples, 8013I, Italy; ${ }^{3}$ Dermatology Unit, \\ Department of Mental and Physical \\ Health and Preventive Medicine, \\ Università degli Studi della Campania \\ "Luigi Vanvitelli”, Naples, 80I3I, Italy
}

\begin{abstract}
Primary cutaneous marginal zone lymphoma (PC-MZL) is a B-cell lymphoma arising in the skin. Although it is a rare disease, PC-MZL accounts for $20-40 \%$ of all primary cutaneous B-cell lymphoma in Western Countries. The aetiology and the pathogenesis of PCMZL are poorly understood, as it generally lacks the chromosomal translocations most typically present in marginal zone lymphomas of other sites. The diagnosis of PC-MZL may be challenging, due to the rarity of the disease, and needs the competence of different professional figures, including the dermatologist and the pathologist. Furthermore, the management of the patient after the diagnosis is complex and involves the dermatologist, the haematologist, the surgeon, the radiotherapist and the radiologist. The aim of this review is to describe the clinical and histological findings for the diagnosis of PC-MZL, and the state of art for the management of the patient.
\end{abstract}

Keywords: marginal zone lymphoma, cutaneous lymphoma, Borrelia burgdorferi, immunohistochemistry, dermoscopy

\section{Introduction}

Primary cutaneous B-cell lymphomas (PC-BCLs) are a heterogeneous group of non-Hodgkin lymphomas originally arising in the skin. ${ }^{1}$ As most primary cutaneous lymphomas are T-cell neoplasms, PC-BCLs are rare, accounting for 25\% of all primary cutaneous lymphomas. Most frequent PC-BCLs are primary cutaneous follicle centre lymphoma, primary cutaneous marginal zone lymphoma (PC-MZL), and primary cutaneous diffuse large B-cell lymphoma, leg type (Figure 1). ${ }^{1}$ The group includes other extremely rare histotypes, like intravascular large B-cell lymphoma, and provisional entity like Epstein-Barr Virus (EBV)-positive mucocutaneous ulcer. ${ }^{1}$ However, other B-cell lymphomas may anecdotally arise primarily in the skin, as well as systemic lymphomas may involve the skin during their course. ${ }^{2}$

PC-MZL was included in the large group of extranodal marginal zone lymphoma of mucosa-associated lymphoid tissue (MALT) by the last 2017 World Health Organization revision of the classification of haematological neoplasms. ${ }^{1}$ PC-MZL accounts for about $20-40 \%$ of all PC-BCLs in Western Countries, with an estimated incidence of 0.4 per $1,000,000$ per year in the United States. ${ }^{3}$ PC-MZL derives from post-germinal centre memory B-cells but its aetiology is substantially unknown. Some evidences about immunoglobulin variable region gene analysis support the existence of a link between a chronic antigenic stimulation and the development of a neoplastic lymphoid clone. ${ }^{4}$ Different associations have been
Correspondence: Renato Franco Pathology Unit, Department of Mental and Physical Health and Preventive Medicine, Università degli Studi della Campania "Luigi Vanvitelli", Via Luciano Armanni 5, Naples, 80138, Italy Tel +3908I5664084

Email renato.franco@unicampania.it 


\section{Primary cutaneous lymphomas}

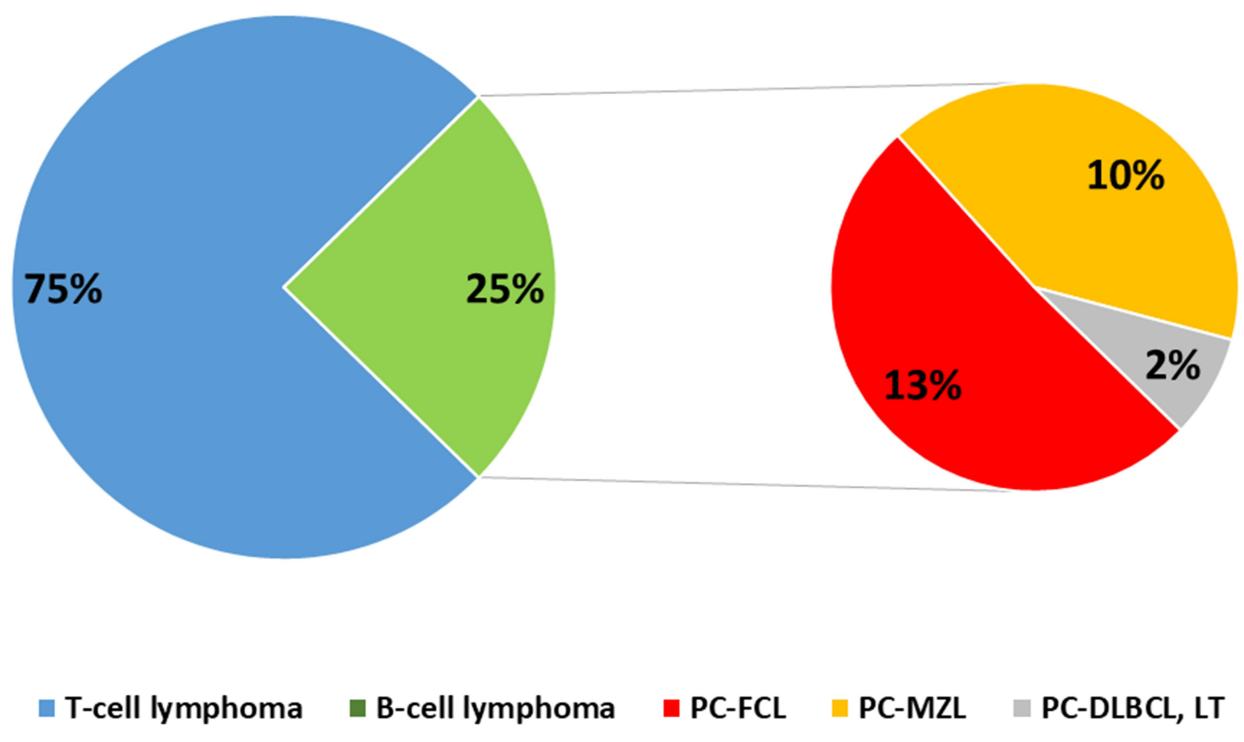

Figure I Frequency distribution of primary cutaneous lymphomas.

reported to date: infectious disease (including Borrelia burgdorferi, Helicobacter pylori, Hepatitis C and EBV), medications (including methotrexate, cyclosporine, antidepressant), influenza (flu) or viral hepatitis A vaccination. ${ }^{5-9}$ Moreover, associations with autoimmune diseases (including rheumatoid arthritis, Hashimoto thyroiditis, Sjogren syndrome, polyarteritis nodosa, ulcerative colitis) have been described. ${ }^{10}$ In this setting, chronic infection by Borrelia burgdorferi was hypothesised to have a role in the pathogenesis of PC-MZL at least in some geographic locations, but its effective role is still debatable Indeed, some series have demonstrated Borrelia infection in up to $40 \%$ cases, but the results have not been confirmed by other series. ${ }^{5}$ Furthermore, anecdotal cases associated to tattoos and vaccinations have been reported. ${ }^{11,12}$

PC-MZLs generally lack the chromosomal translocations most typically present in MALT lymphomas of other sites. However, some cases have been reported showing both the translocations $\mathrm{t}(14 ; 18)(\mathrm{q} 32 ; \mathrm{q} 21) I G H / B C L 2$ and $\mathrm{t}$ $(14 ; 18)(\mathrm{q} 32 ; \mathrm{q} 21) I G H / M A L T 1 .^{13}$

PC-MZL is an indolent lymphoma with rare dissemination to extra-cutaneous sites and excellent prognosis. ${ }^{1}$ Cutaneous relapses may occur in about $20-30 \%$ of cases, more commonly in patients with multifocal skin involvement, and spontaneous regression was also recorded. ${ }^{14,15}$ Extra-cutaneous spread or transformation to high-grade lymphoma is exceptional. ${ }^{1}$

\section{Dermatological and Dermoscopical Findings}

PC-MZL usually presents as solitary or multiple not ulcerated skin lesions represented by red to violaceous papules, or more rarely plaques and nodules (Figure 2A). ${ }^{16}$ Although some paediatric cases have been recorded, the lesions are usually localized on the trunk and arms of middle-aged adults. ${ }^{16}$ Systemic symptoms are generally absent. Dermoscopy could play an adjuvant role for the diagnosis of PC-MZL, showing a salmon-coloured background and serpentine blood vessels (Figure 2B). ${ }^{17-19}$ However, dermoscopic differential diagnosis is broad and includes many entities, like arthropod bites, amelanotic melanoma, basal cell carcinoma and others. Consequently, histological evaluation is mandatory for a definite diagnosis. The excisional biopsy is more representative and should be always preferred, but an incisional punch biopsy could be performed in some instances. As PC-BCLs often involve the deep tissue, the biopsy should always include the hypodermic fat tissue. 

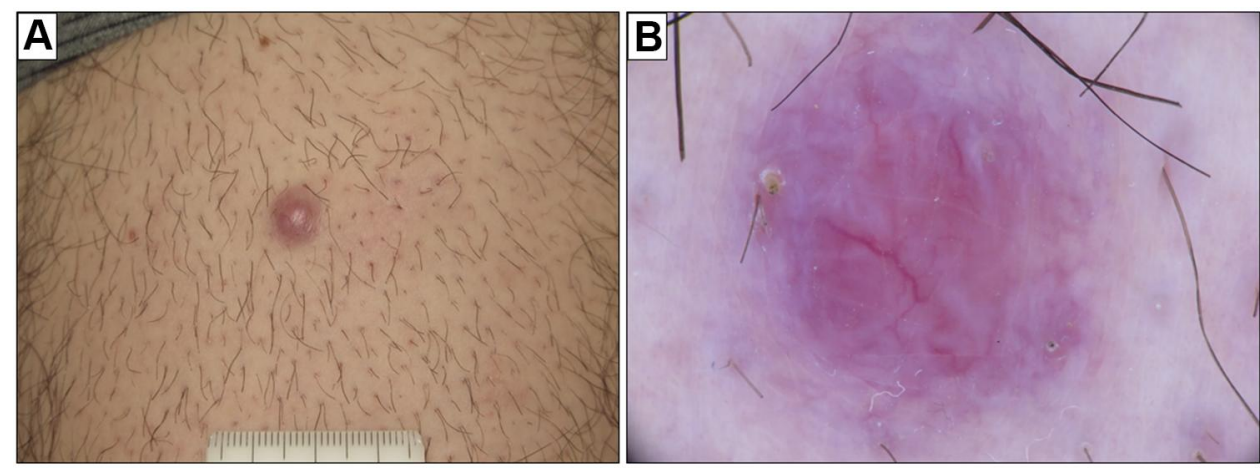

Figure 2 Primary cutaneous marginal zone lymphoma: clinical findings. (A) Male, 18 years old. Small erythematous papule on the volar surface of the left thigh. (B) Dermoscopically, the lesion appeared as a salmon-coloured area with prominent blood vessels with serpentine (linear-irregular) morphology

The clinical diagnosis may be challenging, and the differential diagnosis includes cutaneous pseudolymphomas, as well as other primary or secondary cutaneous B-cell o T-cell lymphomas. ${ }^{20}$ Pseudolymphomatous folliculitis (PLF), a poorly defined entity among the cutaneous pseudolymphomas, presents clinically as a solitary domeshaped or flat to elevated nodule, located on the face, the scalp and the trunk. ${ }^{21}$ Primary cutaneous follicle centre lymphoma presents as solitary or - less commonly grouped erythematous or violaceous papules, plaques and/or nodules, usually located on the trunk and headneck. ${ }^{22}$ Primary cutaneous diffuse large B-cell lymphoma, leg type is a rare aggressive $\mathrm{PC}-\mathrm{BCL}$, presenting as rapidly growing erythematous or cyanotic nodules and/or plaques, usually located on one or both legs. ${ }^{23}$ "B-Symptoms" (fever, weight loss, night sweats) and extra-cutaneous diffusion are common. ${ }^{1}$ Differential diagnosis of PC-MZL also includes Lupus Erythematosus Tumidus (LET), Jessner's lymphocytic infiltrate and granuloma faciale. LET is characterized by non-scarring, erythematous, succulent, urticaria-like plaques without surfaces changes. ${ }^{24}$ Jessner's lymphocytic infiltrate is characterized by multiple asymptomatic erythematous papules or plaques with arciform or annular pattern, commonly located on the face, neck and upper trunk. ${ }^{25}$ Both Jessner's lymphocytic infiltrate and LET probably represent part of the spectrum of cutaneous lupus. Granuloma faciale is characterized by single or multiple erythematous papules, plaques or nodules on the face. ${ }^{26}$

Other lymphomas may rarely occur at the skin as primary localization or secondary involvement by a systemic disease. ${ }^{2}$ Lymphoplasmacytic lymphoma is a low-grade B-cell lymphoma rarely involving the skin, with a substantial subset of cases being associated with
Waldenstrom macroglobulinaemia. ${ }^{16}$ Although most patients are asymptomatic, anemia or blood hyperviscosity may be possible. ${ }^{27}$ Cutaneous localizations are rare and present as purple, sometimes ulcerated, nodules. In case of association with Waldenstrom macroglobulinaemia, diffuse urticarial rash and IgM paraproteinemia may arise (Schnitzler syndrome).$^{28}$ Rare cases of cutaneous involvements have been reported in patients affected by multiple myeloma or plasma cell leukaemia. ${ }^{29}$ In these cases, single or multiple violaceous cutaneous nodules have been described, but erythematous plaques may also be observed. ${ }^{29}$ In plasma cell myeloma, hyperkeratotic spicules may occur, mainly on the face. Primary cutaneous CD4-positive small/medium T-cell lymphoma is a rare indolent disease with insidious clinical evolution, classically presenting a solitary asymptomatic nodule, plaque or tumour on the face, the neck or the trunk. ${ }^{30}$

\section{Pathological Findings}

PC-BCLs as a group share some common histological findings, which may allow distinguishing them from T-cells lymphomas on a morphological basis. The overall architecture is usually nodular rather than band-like, the papillary dermis is spared (a "Grenz-zone" is present), and the epidermotropism and/or folliculotropism is absent. ${ }^{16}$ PC-MZL usually - but not always - shares these common "B-cell" histological findings. PC-MZL always involves the reticular dermis, sparing the papillary dermis and epidermis, and often involves the hypodermis. The overall architecture is more often nodular, but it may also be diffuse. Ulceration of the epidermis is exceptional. ${ }^{16}$ Periadnexal infiltration is often present, but lympho-epithelial lesions are uncommon are not critical for the diagnosis. ${ }^{23}$ Lymphoid follicles characterized by reactive germinal center and preserved mantle 
zone are frequently present. The follicles may play an important role for diagnostic purpose, as they may show germinal center colonization by marginal zone cells, and partial destruction of follicular dendritic cell meshwork. The lymphoid population is variably mixed, including centrocyte-like marginal zone B cells, monocytoid B-cells, lymphoplasmacytic cells, cells resembling centroblasts and immunoblasts, and reactive $\mathrm{T}$ cells. Plasma cells are variably present, more often at the periphery of the nodules, but Dutcher bodies are infrequent. ${ }^{31}$ A variable amount of inflammatory cells may be admixed to the neoplastic population, including T-cell lymphocytes, histiocytes, mast cells, and eosinophils. ${ }^{32}$ Histological findings are shown in Figure 3. Some morphological variants of PC-MZL have been described, including small cell lymphocytic variant, monocytoid variant and variant with diffuse plasmacytic differentiation. $^{33-39}$ Morphological findings of PC-MZL lack specificity and the diagnosis may be one of the most challenging in the setting of cutaneous lymphoid neoplasms. The lympho-epithelial lesions, which play an important role in diagnosis of mucosa-associated marginal zone lymphomas, are useless in case of PC-MZL. Indeed, they are often absent, and on the other hand, they may be present in reactive disorders. The reactive inflammatory lymphoid and not lymphoid - population may outnumber the neoplastic cells, and reactive germinal centers in the context of the neoplasm may simulate an inflammatory disease. On the other way, cases with prominent lymphoplasmacytoid or plasmacytoid differentiation may simulate lymphoplasmacytic lymphoma or myeloma. Consequently, histological diagnosis of PC-MZL is challenging and always relies on the comprehensive integration of morphological and immunohistochemical findings and clonal analysis.

Immunohistochemically, PC-MZL is characterized by the expansion of the marginal zone cellular population, which is positive for $\mathrm{CD} 20$ and $\mathrm{Bcl} 2$. The reactive germinal centers are positive for Bcl6 and CD10 and negative for Bc12. CD21 and CD23 immunostains may be helpful to highlight the partial destruction of follicular dendritic cell meshwork. Plasma cells are more often polyclonal by testing Immunoglobulin (Ig) light chain immunostains. Myeloid cell nuclear differentiation antigen (MNDA) has recently emerged as a useful marker in MZL, but its diagnostic
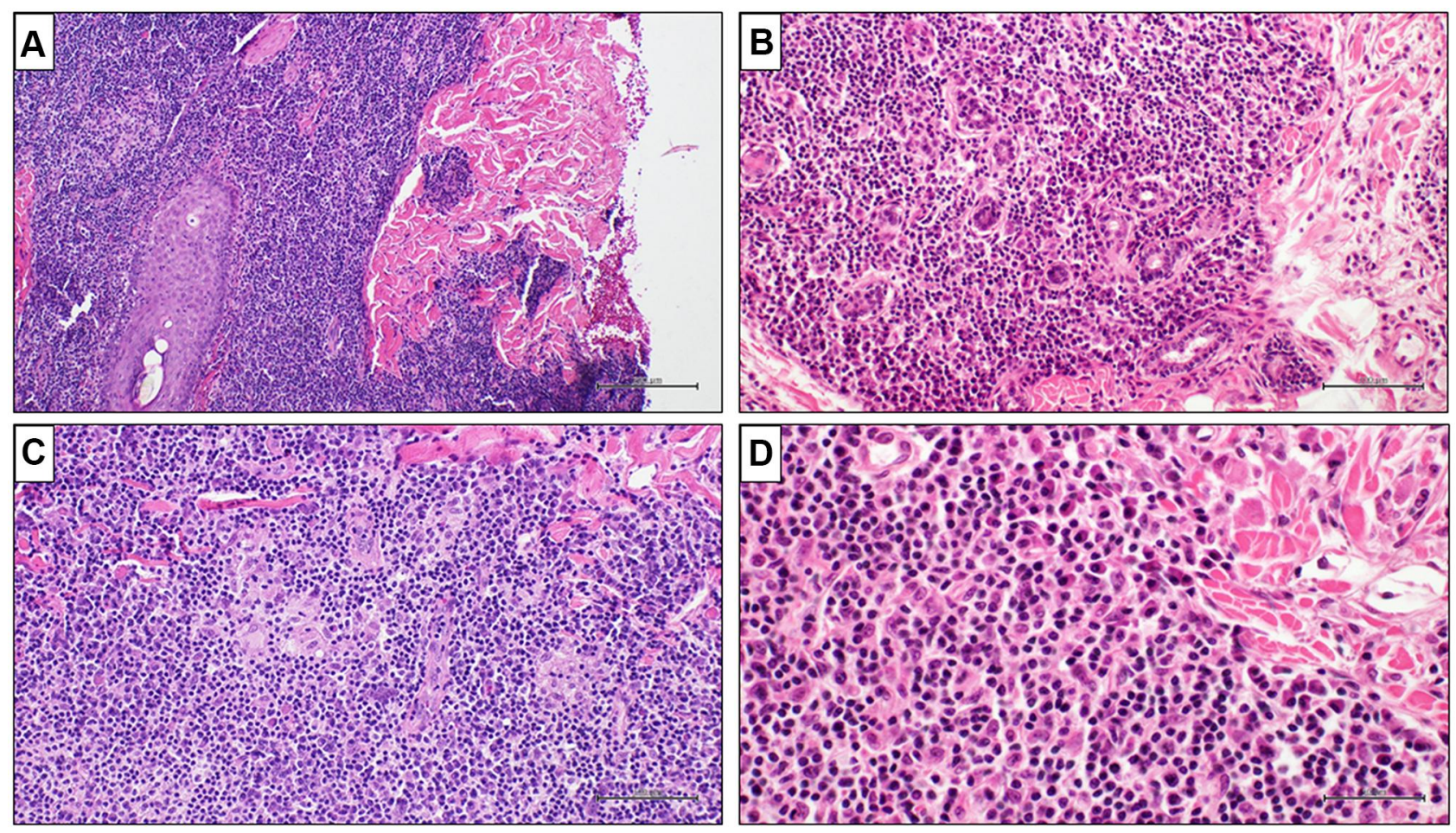

Figure 3 Primary cutaneous marginal zone lymphoma: histological findings. A diffuse lymphoid population in the reticular dermis, extending along a hair ((A) H\&E, original magnification 20x). In the deeper dermis, some sweat glands are entrapped in the lymphoid infiltrate, in absence of lympho-epithelial lesions ((B) H\&E, original magnification 40x). A granulomatous reaction is possible at the periphery of the infiltrate $((\mathbf{C}) \mathrm{H \& E}$, original magnification 40x). The lymphoid population is heterogeneous, including mature lymphocytes, lympho-plasmacytoid cells and plasma cells ((D) H\&E, original magnification 200x).

Abbreviation: H\&E, haematoxylin and eosin. 
value in case of PC-MZL is still poorly investigated. Verdanet et al have recently reported MNDA positivity in 4 out of 13 cases of PC-MZL (30.8\%). ${ }^{40}$ Primary cutaneous plasmacytoid dendritic cells have been hypothesised to have a diagnostic role, as large clusters have been observed in PCMZL rather than in reactive B-cell infiltrates. ${ }^{41}$ Actually, two groups of PC-MZL are defined on the basis of the expression of surface immunoglobulins: the "class-switched" group expresses IgG or, more rarely, IgA and IgE, and is characterized by a nodular and scattered distribution of B-cells, and many T-cells, mainly Th2. The "non-class-switched" group expresses IgM and is characterized by a diffuse distribution of B-cells, and a less represented T-cell population. ${ }^{42}$ A variable number of IgG-positive PC-MZLs are IgG4positive, ranging from $13 \%$ to $40 \%$ in different series, and are not associated with systemic IgG4-related disease. ${ }^{31}$ Hypermutation and antigenic pressure has been demonstrated in such subset of PC-BCL. ${ }^{43}$ Immunohistochemical findings are shown in Figure 4. The most useful immunohistochemical markers are listed in Table 1.

\section{Patient Management}

As PC-MZL is an indolent lymphoma, systemic spread and bone marrow infiltration are rare events. However, instrumental staging is mandatory at the time of the first diagnosis, using superficial and abdominal lymph node ultra-sound
(US), and total-body computed tomography (CT). ${ }^{16}$ Although combined CT and positron emission tomography (CT/PET) is actually the gold standard for staging purpose in case of primary cutaneous follicle centre lymphoma and primary cutaneous diffuse large B-cell lymphoma, leg type, its introduction as a routine staging test in case of PC-MZL is still debated. ${ }^{44}$ Bone marrow biopsy is not mandatory, but it may be useful in the case of single or multiple cell line cytopenia. ${ }^{22}$ PC-MZL staging yet requires a careful history and clinical examination and laboratory tests such as: blood count, LDH, Erythrocyte Sedimentation Rate (ESR), C-reactive protein (CRP), beta-2 microglobulin, Serum Protein Electrophoresis (SPE), HIV antibodies, HBV antibodies, AST, ALT, creatinine, amylase, lipase, bilirubin, HCV Antibodies. ${ }^{45-52}$ Moreover, Borrelia burgdorferi serology is recommended in endemic areas. ${ }^{5,7}$ Tumor Node Metastases (TNM) classification of cutaneous lymphoma other than mycosis fungoides/Sézary syndrome is an available staging system for PC-MZL (Table 2). ${ }^{52}$ However, T stage has no prognostic value in PC-MZL, while the presence of a single cutaneous lesion has proved an independent prognostic significance on disease-free survival. ${ }^{53}$ In addition, the International Extranodal Lymphoma Study Group (IELSG) recently proposed a specific prognostic score for patients with indolent PC-BCLs, demonstrating that elevated LDH, more than 2 skin lesions, and nodular lesions may affect the
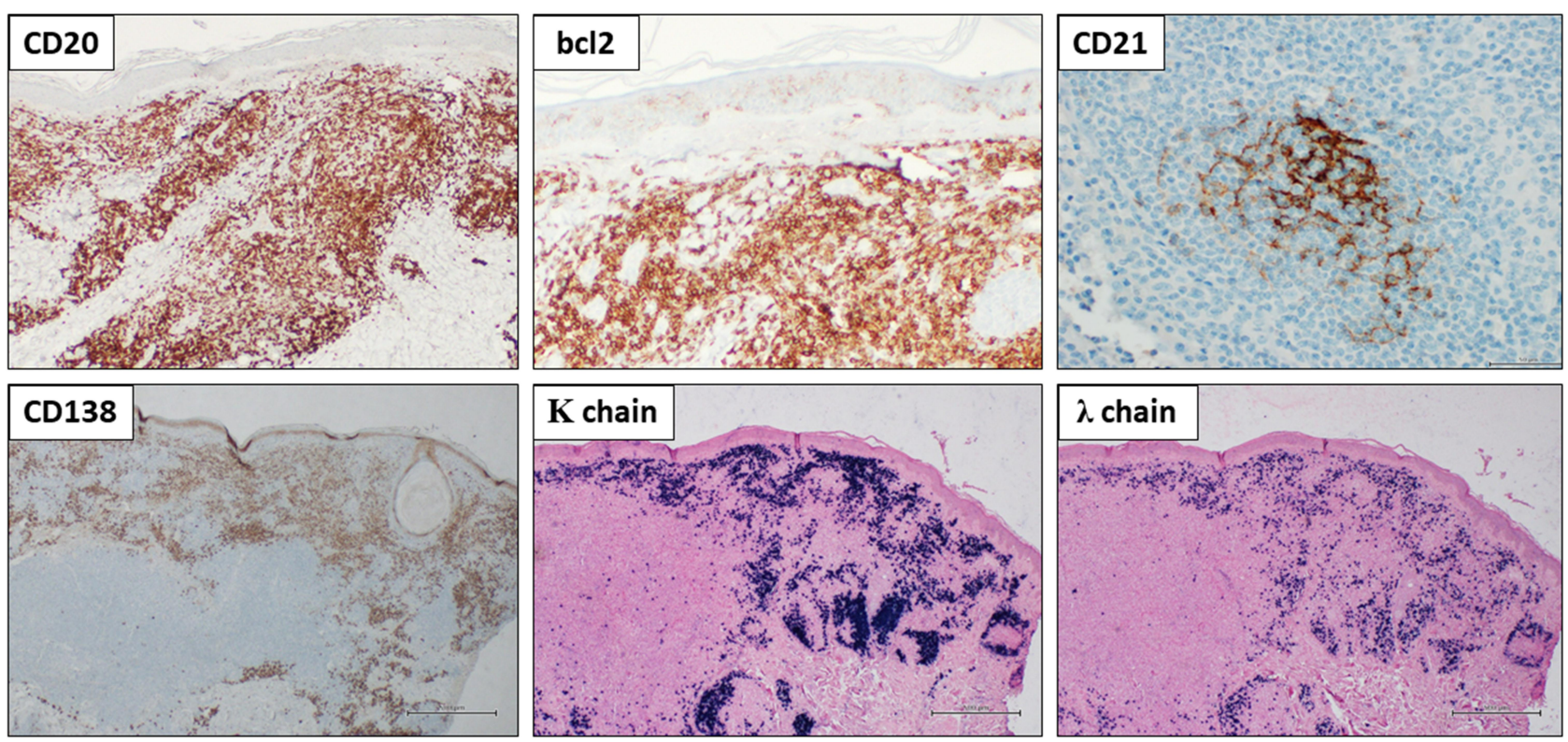

Figure 4 Primary cutaneous marginal zone lymphoma: immunohistochemical findings. Lymphoid population showing positivity for CD20 and Bcl2. CD2I immunostaining highlights a partially destroyed network of follicular dendritic cells. An abundant reactive population of CDI38-positive plasma cells is present at the periphery of the infiltrate. In-situ hybridization (ISH) demonstrates a kappa:lambda ratio of about 3:I. 
Table I Main Contribution of Immunohistochemical Markers to Diagnosis of PCMZL

\begin{tabular}{|c|c|}
\hline Marker & Contribution \\
\hline CD20 & $\begin{array}{l}\text { Results positive in both neoplastic and } \\
\text { reactive B-cells. } \\
\text { Highlights the overall architecture of the } \\
\text { population. }\end{array}$ \\
\hline CD3 & $\begin{array}{l}\text { Results positive in the reactive T-cells in the } \\
\text { background. }\end{array}$ \\
\hline CDIO and Bcl6 & $\begin{array}{l}\text { Negative in neoplastic cells. } \\
\text { Result positive in the reactive germinal } \\
\text { centres, if present. } \\
\text { Allows to exclude the diagnosis of primary } \\
\text { cutaneous follicular cell lymphoma. }\end{array}$ \\
\hline CD2I and CD23 & $\begin{array}{l}\text { Negative in neoplastic cells. } \\
\text { Highlight the network of follicular dendritic } \\
\text { cells in reactive germinal centres, if present. } \\
\text { May highlight partial destruction of follicular } \\
\text { dendritic cells meshwork, consequence of } \\
\text { germinal center colonization by marginal } \\
\text { zone cells. }\end{array}$ \\
\hline CD5 & $\begin{array}{l}\text { Negative in neoplastic cells. } \\
\text { Results positive in T-cells and in mantle cells, } \\
\text { if lymphoid follicles are present. } \\
\text { Allows to exclude the diagnosis of mantel cell } \\
\text { lymphoma. } \\
\text { It should always be compared with CD3. }\end{array}$ \\
\hline $\mathrm{Bcl} 2$ & $\begin{array}{l}\text { Positive in neoplastic cells. } \\
\text { Results positive in a subset of T-cells. } \\
\text { It should always be compared with CD3. }\end{array}$ \\
\hline Cyclin DI & $\begin{array}{l}\text { Negative in neoplastic cells. } \\
\text { Allows to exclude mantle cell lymphoma. }\end{array}$ \\
\hline CDI38 & $\begin{array}{l}\text { Positive in both reactive and neoplastic } \\
\text { plasma-cells and plasmacytic cells. }\end{array}$ \\
\hline $\begin{array}{l}\text { Kappa and lambda lg } \\
\text { light chains }\end{array}$ & $\begin{array}{l}\text { Positive in plasma-cells. } \\
\text { May show a clonality in neoplastic plasma- } \\
\text { cells. } \\
\text { Plasma-cells in PCMZL may be reactive. }\end{array}$ \\
\hline CD43 & $\begin{array}{l}\text { Positive in a subset of PC-MZL. } \\
\text { May be positive in other B-cell lymphomas. }\end{array}$ \\
\hline MNDA & Positive in a subset of PC-MZL. \\
\hline
\end{tabular}

progression-free survival. ${ }^{54}$ However, no factor showed any meaningful difference in overall survival. ${ }^{54}$

\section{Treatment}

PC-MZL is an indolent tumour with excellent prognosis, and overtreatment should be avoided. Several treatment
Table 2 ISCL/EORTC Staging System for Primary Cutaneous Lymphomas

\begin{tabular}{|l|}
\hline T \\
\hline TI: solitary skin involvement \\
TIa: solitary lesion $<5 \mathrm{~cm}$ diameter \\
TIb: solitary lesion $>5 \mathrm{~cm}$ diameter \\
\hline T2: regional skin involvement \\
T2a: all-disease-encompassing in a $<15 \mathrm{~cm}$ diameter circular area \\
T2b: all-disease-encompassing in a $>15 \mathrm{~cm}$ and $<30$ cm diameter \\
circular area \\
T2c: all-disease-encompassing in a $>30 \mathrm{~cm}$ diameter circular area \\
\hline T3: generalized skin involvement \\
T3a: multiple lesions involving 2 non-contiguous body regions \\
T3b: multiple lesions involving $\geq 3$ body regions \\
\hline $\mathbf{N}$ \\
\hline N0: no clinical or pathologic lymph node involvement \\
\hline $\begin{array}{l}\text { NI: involvement of I peripheral lymph node region that drains an } \\
\text { area of current or prior skin involvement }\end{array}$ \\
\hline $\begin{array}{l}\text { N2: involvement of } 2 \text { or more peripheral lymph node regions or } \\
\text { involvement of any lymph node region that does not drain an area of } \\
\text { current or prior skin involvement }\end{array}$ \\
\hline N3: involvement of central lymph nodes \\
\hline $\mathbf{M}$ \\
\hline M0: no evidence of extracutaneous non-lymph node disease \\
\hline MI: extracutaneous non-lymph node disease present \\
\hline
\end{tabular}

options are available depending on disease features (size and site of skin involvement) and patient findings (age and general health). A "wait-and-see" strategy can be followed in selected patients. This strategy consists in the observation, treating the patient only in the rare cases of systemic symptoms. ${ }^{55}$ According to European Organization for Research and Treatment of Cancer/International Society of Cutaneous Lymphoma (EORTC/ISCL) consensus recommendation, solitary and localized lesions can be treated by radiotherapy, surgery alone or surgery followed by radiotherapy, with curative intent. These treatments usually are sufficient for complete remission (>95\%). Surgical excision and radiotherapy represent the first-line therapy in case of solitary lesion.

When used as first-line therapy, radiotherapy may be sufficient to achieve complete remission of the neoplasm. A total dose ranging between 20 and $36 \mathrm{~Gy}$ is recommended by the actual guidelines, with good results in 
terms of response to therapy and tolerability of toxicity. ${ }^{56}$ However, increasing evidences support the efficacy of lower dosages, which greatly reduce side effects. ${ }^{57}$ Indeed, the classic protocols of radiotherapy are increasingly modifying the intensity of treatments to obtain the best response with a reduced toxicity. Several studies proposed the use of low-dose radiotherapy (LDRT) (4 Gy in 2 sessions or 8 Gy in 2 sessions), showing high response rates with reduction of toxicity. ${ }^{58}$ LDRT may represent a good treatment choice mainly in case of relapsed neoplasm or multifocal disease. ${ }^{58}$ However, some Authors proposed LDRT as first-line therapy with a good rate of remission and low toxicity, reserving standard dose RT only in case of relapse. ${ }^{59}$

Topical therapies play a minor role for treatment of PC-MZL. Topical corticosteroids with high potency represent a potential alternative in case of plaques with mild infiltration, while intralesional injections may be used in case of more thickened skin lesions. ${ }^{60}$ However, disease recurrences and adverse effects have been reported in these cases. $^{60}$ Intralesional therapy using interferon- $\alpha$ (IFN- $\alpha$ ) and rituximab may be used as second-line treatment or in the patients with multiple cutaneous lesions. ${ }^{61,62}$ However, there treatments may be burdened by pain at injection site and potential systemic reaction. ${ }^{62}$ Genetically modified viruses (adenovirus interferon- $\gamma$ ) are being tested as intralesional therapy. ${ }^{63}$

In patients with Borrelia burgdorferi infection, antibiotic treatment (doxycycline $100 \mathrm{mg}$ bid 3 weeks or cefotaxime i.v.) should be performed, but not all cases respond to therapy. ${ }^{64}$

Systemic therapies are usually unnecessary in PC-MZL and it should be limited to cases with systemic spread. These cases are exceeding rare, and consequently data about the use of systemic therapy in PC-MZL are lacking. However, the most useful drug in this setting is rituximab, alone or in combination with chlorambucil, fludarabine, cyclophosphamide and vincristine in CVP, bendamustine. ${ }^{65}$ Moreover, new therapeutic options are being evaluated for the treatment of relapsed or refractory indolent lymphomas, such as lenalidomide, ibrutinib, idelalisib. ${ }^{66-69}$

\section{Conclusion}

PC-MZL is an indolent lymphoma with an excellent prognosis, and the extra-cutaneous secondary dissemination is exceeding rare. The diagnosis may be challenging, from both a clinical and histological point of view, and differential diagnosis is wide, including benign and malignant diseases. Surgery and radiotherapy represent the best therapy in most cases.

\section{Abbreviations}

PC-MZL, primary cutaneous marginal zone lymphoma; PC-BCL, primary cutaneous B-cell lymphoma; EBV, Epstein-Barr Virus; MALT, mucosa-associated lymphoid tissue; PCDLBCL, LT, primary cutaneous diffuse large B-cell lymphoma, leg type; CD, cluster of differentiation; Ig, immunoglobulin; MNDA, myeloid cell nuclear differentiation antigen; LDH, Lactate Dehydrogenase; PET, positron emission tomography; CT, computed tomography; US, ultra sound; ESR, Erythrocyte Sedimentation Rate; CRP, C-reactive protein; SPE, Serum Protein Electrophoresis; HIV, Human Immunodeficiency Virus; HBV, hepatitis B virus; AST, aspartate transaminase; ALT, alanine transaminase; HCV, Human Immunodeficiency Virus; IELSG, International Extranodal Lymphoma Study Group; EORTC/ISCL, European Organization for Research and Treatment of Cancer/International Society of Cutaneous Lymphoma.

\section{Disclosure}

The authors report no conflicts of interest in this work.

\section{References}

1. Willemze R, Cerroni L, Kempf W, et al. The 2018 update of the WHO-EORTC classification for primary cutaneous lymphomas. Blood. 2019;133(16):1703-1714. doi:10.1182/blood-2018-11-881268

2. Pinter-Brown LC. Diagnosis and management of cutaneous B-cell lymphoma. Dermatol Clin. 2015;33(4):835-840. doi:10.1016/j. det.2015.05.003

3. Bradford PT, Devesa SS, Anderson WF, Toro JR. Cutaneous lymphoma incidence patterns in the United States: a population-based study of 3884 cases. Blood. 2009;113(21):5064-5073. doi:10.1182/ blood-2008-10-184168

4. Perez M, Pacchiarotti A, Frontani M, et al. Primary cutaneous B-cell lymphoma is associated with somatically hypermutated immunoglobulin variable genes and frequent use of VH1-69 and VH4-59 segments. Br J Dermatol. 2010;162(3):611-618. doi:10.1111/j.13652133.2009.09576.x

5. Perrone S, D’Elia GM, Annechini G, Pulsoni A. Infectious aetiology of marginal zone lymphoma and role of anti-infective therapy. Mediterr J Hematol Infect Dis. 2016;8(1):e2016006. doi:10.4084/ mjhid.2016.006

6. Ponzoni M, Ferreri AJ. Bacteria associated with marginal zone lymphomas. Best Pract Res Clin Haematol. 2017;30(1-2):32-40. doi:10.1016/j.beha.2017.01.001

7. Foster LH, Portell CA. The role of infectious agents, antibiotics, and antiviral therapy in the treatment of extranodal marginal zone lymphoma and other low-grade lymphomas. Curr Treat Options Oncol. 2015;16(6):28. doi:10.1007/s11864-015-0344-6

8. Bende RJ, van Maldegem F, van Noesel CJ. Chronic inflammatory disease, lymphoid tissue neogenesis and extranodal marginal zone B-cell lymphomas. Haematologica. 2009;94(8):1109-1123. doi:10.3324/haematol.2009.005983 
9. Suarez F, Lortholary O, Hermine O, Lecuit M. Infection-associated lymphomas derived from marginal zone B cells: a model of antigen-driven lymphoproliferation. Blood. 2006;107(8):3034-3044. doi:10.1182/blood-2005-09-3679

10. Fallah M, Liu X, Ji J, Försti A, Sundquist K, Hemminki K. Autoimmune diseases associated with non-Hodgkin lymphoma: a nationwide cohort study. Ann Oncol. 2014;25(10):2025-2030. doi:10.1093/annonc/mdu365

11. Chandler JB, Waldman R, Sloan SB, Rose MG, Wong EY. Cutaneous marginal zone lymphoma following anthrax vaccination. Ann Hematol. 2020. doi:10.1007/s00277-020-04336-4

12. Shinohara MM, Nguyen J, Gardner J, Rosenbach M, Elenitsas R. The histopathologic spectrum of decorative tattoo complications. J Cutan Pathol. 2012;39(12):1110-1118. doi:10.1111/cup.12023

13. Palmedo G, Hantschke M, Rütten A, et al. Primary cutaneous marginal zone B-cell lymphoma may exhibit both the $\mathrm{t}(14 ; 18)(\mathrm{q} 32 ; \mathrm{q} 21)$ IGH/BCL2 and the $t(14 ; 18)(q 32 ; q 21)$ IGH/MALT1 translocation: an indicator for clonal transformation towards higher-grade B-cell lymphoma? Am J Dermatopathol. 2007;29(3):231-236. doi:10.1097/DAD.0b013e31804795a6

14. Tang X, Tang J, Liu W, Wang L. Primary cutaneous marginal zone B-cell lymphoma with unusual manifestation and spontaneous regression. Indian $J$ Dermatol Venereol Leprol. 2020;86 (4):428-431. doi:10.4103/ijdvl.IJDVL_516_19

15. Franco R, Fernández-Vázquez A, Mollejo $\mathrm{M}$, et al. Cutaneous presentation of follicular lymphomas. Mod Pathol. 2001;14(9):913-919. doi:10.1038/modpathol.3880411

16. Vitiello P, Sica A, Ronchi A, Caccavale S, Franco R, Argenziano G. Primary cutaneous B-cell lymphomas: an update. Front Oncol. 2020;10:651. doi:10.3389/fonc.2020.00651

17. Piccolo V, Mascolo M, Russo T, Staibano S, Argenziano G. Dermoscopy of primary cutaneous B-cell lymphoma (PCBCL). $J$ Am Acad Dermatol. 2016;75(4):e137-e139. doi:10.1016/j. jaad.2016.02.1217

18. Piccolo V, Russo T, Agozzino M, et al. Dermoscopy of cutaneous lymphoproliferative disorders: where are we now? Dermatology. 2018;234:131-136. doi:10.1159/000490412

19. Geller S, Marghoob AA, Scope A, Braun RP, Myskowski PL. Dermoscopy and the diagnosis of primary cutaneous B-cell lymphoma. J Eur Acad Dermatol Venereol. 2018;32(1):53-56. doi: $10.1111 / j d v .14549$

20. Baldassano MF, Bailey EM, Ferry JA, Harris NL, Duncan LM. Cutaneous lymphoid hyperplasia and cutaneous marginal zone lymphoma: comparison of morphologic and immunophenotypic features. Am J Surg Pathol. 1999;23(1):88-96. doi:10.1097/00000478199901000-00010

21. Arai E, Okubo H, Tsuchida T, Kitamura K, Katayama I. Pseudolymphomatous folliculitis: a clinicopathologic study of 15 cases of cutaneous pseudolymphoma with follicular invasion. $\mathrm{Am}$ $J \quad$ Surg Pathol. 1999;23:1313-1319. doi:10.1097/00000478199911000-00001

22. Wilcox RA. Cutaneous B-cell lymphomas: 2019 update on diagnosis, risk stratification, and management. Am J Hematol. 2018;93:1427-1430. doi:10.1002/ajh.25224

23. Cho-Vega JH, Vega F, Rassidakis G, et al. Primary cutaneous marginal zone B cell lymphoma. Am J Clin Pathol. 2006;125:S38-S49. doi:10.1309/CVFYBQNMX1PKNAA7

24. Patsinakidis N, Kautz O, Gibbs BF, Raap U. Lupus erythematosus tumidus: clinical perspectives. Clin Cosmet Investig Dermatol. 2019;12:707-719. doi:10.2147/CCID.S166723

25. Rémy-Leroux V, Léonard F, Lambert D, et al. Comparison of histopathologic-clinical characteristics of Jessner's lymphocytic infiltration of the skin and lupus erythematosus tumidus: multicenter study of 46 cases. J Am Acad Dermatol. 2008;58(2):217-223. doi:10.1016/ j.jaad.2007.09.039
26. Lallas A, Argenziano G, Apalla Z, et al. Dermoscopic patterns of common facial inflammatory skin diseases. J Eur Acad Dermatol Venereol. 2014;28(5):609-614. doi:10.1111/jdv.12146

27. Tees MT, Flinn IW. Chronic lymphocytic leukemia and small lymphocytic lymphoma: two faces of the same disease. Expert Rev Hematol. 2017;10(2):137-146. doi:10.1080/17474086.2017.1270203

28. Gusdorf L, Lipsker D. Schnitzler syndrome: a review. Curr Rheumatol Rep. 2017;19(8):46. doi:10.1007/s11926-017-0673-5

29. Torne R, Su WP, Winkelmann RK, Smolle J, Kerl H. Clinicopathologic study of cutaneous plasmacytoma. Int J Dermatol. 1990;29(8):562-566. doi:10.1111/j.1365-4362.1990. tb03469.x

30. Gru AA, Wick MR, Eid M. Primary cutaneous CD4+ small/medium T-cell lymphoproliferative disorder-clinical and histopathologic features, differential diagnosis, and treatment. Semin Cutan Med Surg. 2018;37(1):39-48. doi:10.12788/j.sder.2018.006

31. Carlsen ED, Swerdlow SH, Cook JR, et al. Class-switched primary cutaneous marginal zone lymphomas are frequently IgG4-positive and have features distinct from IgM-positive cases. Am J Surg Pathol. 2019;43:1403-1412. doi:10.1097/PAS.0000000000001363

32. Cerroni L, Signoretti S, Höfler G, et al. Primary cutaneous marginal zone B-cell lymphoma: a recently described entity of low-grade malignant cutaneous B-cell lymphoma. Am J Surg Pathol. 1997;21:1307-1315. doi:10.1097/00000478-199711000-00005

33. Magro CM, Olson LC. Small cell lymphocytic variant of marginal zone lymphoma: a distinct form of marginal zone lymphoma derived from naïve $B$ cells as a cutaneous counterpart to the naïve marginal zone lymphoma of splenic origin. Ann Diagn Pathol. 2018;34:116-121. doi:10.1016/j.anndiagpath.2018.02.006

34. LeBoit PE, McNutt NS, Reed JA, et al. Primary cutaneous immunocytoma a B-cell lymphoma that can easily be mistaken for cutaneous lymphoid hyperplasia. Am J Surg Pathol. 1994;18:969. doi:10.1097/ 00000478-199410000-00001

35. Rijlaarsdam JU, van der Putte SCJ, Berti E, et al. Cutaneous immunocytomas: a clinicopathologic study of 26 cases. Histopathology. 1993;23:117-125. doi:10.1111/j.1365-2559.1993.tb00469.x

36. Turbiner Geyer J, Ferry JA, Longtine JA, et al. Characteristics of cutaneous marginal zone lymphomas with marked plasmacytic differentiation and a $\mathrm{T}$ cell-rich background. Am J Clin Pathol. 2010;133:59-69. doi:10.1309/AJCPW64FFBTTPKFN

37. Magro CM, Yang A, Fraga G. Blastic marginal zone lymphoma: a clinical and pathological study of 8 cases and review of the literature. Am J Dermatopathol. 2013;35:319-326. doi:10.1097/ DAD.0b013e318267495f

38. Walsh NM, Lano IM, Green P, et al. AL amyloidoma of the skin/ subcutis: cutaneous amyloidosis, plasma cell dyscrasia or a manifestation of primary cutaneous marginal zone lymphoma? Am J Surg Pathol. 2017;41:1069-1076. doi:10.1097/ PAS.0000000000000861

39. Ueberdiek S, Kempf W, Kretschmer L, Schon MP, Mitteldorf C. ALamyloidoma of the skin - a rare manifestation of primary cutaneous marginal zone lymphoma. Am J Dermatopathol. 2019;41:518-521. doi:10.1097/DAD.0000000000001368

40. Verdanet E, Dereure O, René C, et al. Diagnostic value of STMN1, LMO2, HGAL, AID expression and 1p36 chromosomal abnormalities in primary cutaneous B cell lymphomas. Histopathology. 2017;71(4):648-660. doi:10.1111/his.13279

41. Kempf W, Kerl H, Kutzner H. CD123-positive plasmacytoid dendritic cells in primary cutaneous marginal zone B-cell lymphoma: a crucial role and a new lymphoma paradigm. Am J Dermatopathol. 2010;32(2):194-196. doi:10.1097/ DAD.0b013e3181aff9b3

42. Edinger JT, Kant JA, Swerdlow SH. Cutaneous marginal zone lymphomas have distinctive features and include 2 subsets. Am J Surg Pathol. 2010;34(12):1830-1841. doi:10.1097/PAS.0b013e3181f72835 
43. Franco R, Camacho FI, Fernández-Vázquez A, et al. $\operatorname{IgV}(\mathrm{H})$ and bcl6 somatic mutation analysis reveals the heterogeneity of cutaneous B-cell lymphoma, and indicates the presence of undisclosed local antigens. Mod Pathol. 2004;17(6):623-630. doi:10.1038/ modpathol.3800106

44. Albano D, Durmo R, Treglia G, Giubbini R, Bertagna F. 18F-FDG PET/CT or PET Role in MALT Lymphoma: an open issue not ye solved - a critical review. Clin Lymphoma Myeloma Leuk. 2020;20 (3):137-146. doi:10.1016/j.clml.2019.10.006

45. Merli M, Frigeni M, Alric L, et al. Direct-acting antivirals in hepatitis C virus-associated diffuse large B-cell lymphomas. Oncologist. 2019;24(8):e720-e729. doi:10.1634/theoncologist.2018-0331

46. Tonziello G, Pisaturo M, Sica A, et al. Transient reactivation of occult hepatitis B virus infection despite lamivudine prophylaxis in a patient treated for non-Hodgkin lymphoma. Infection. 2013;41 (1):225-229. doi:10.1007/s15010-012-0305-y

47. Pisaturo M, Guastafierro S, Filippini P, et al. Absence of occult HCV infection in patients experiencing an immunodepression condition. Infez Med. 2013;21(4):296-301.

48. Coppola N, Pisaturo M, Guastafierro S, et al. Increased hepatitis $\mathrm{C}$ viral load and reactivation of liver disease in HCV RNA-positive patients with onco-haematological disease undergoing chemotherapy. Dig Liver Dis. 2012;44(1):49-54. doi:10.1016/j.dld.2011.07.016

49. Merli M, Defrancesco I, Visco C, et al. Direct-acting antivirals in relapsed or refractory hepatitis $\mathrm{C}$ virus-associated diffuse large B-cell lymphoma. Leuk Lymphoma. 2020;28:1-7.

50. Bagaglio S, Uberti-Foppa C, Sagnelli C, et al. HIV-1 recombinant forms in immigrants regularly residing in Milan, northern Italy. Infection. 2020;48(4):553-558. doi:10.1007/s15010-020-01434-3

51. Sica A, Casale D, Rossi G, et al. The impact of the SARS-CoV-2 infection, with special reference to the haematological setting. $J \mathrm{Med}$ Virol. 2020;93(1):223-233. doi:10.1002/jmv.26197

52. Kim YH, Willemze R, Pimpinelli N, et al. TNM classification system for primary cutaneous lymphomas other than mycosis fungoides and Sezary syndrome: a proposal of the International Society for Cutaneous Lymphomas (ISCL) and the cutaneous lymphoma task force of the European Organization of Research and Treatment of cancer (EORTC). Blood. 2007;110:479-484. doi:10.1182/blood-200610-054601

53. Zinzani PL, Quaglino P, Pimpinelli N, et al. Prognostic factors in primary cutaneous B-cell lymphoma: the Italian study group for cutaneous lymphomas. J Clin Oncol. 2006;24(9):1376-1382. doi:10.1200/JCO.2005.03.6285

54. Mian M, Marcheselli L, Luminari S, et al. CLIPI: a new prognostic index for indolent cutaneous B cell lymphoma proposed by the international extranodal lymphoma study group (IELSG 11). Ann Hematol. 2011;90(4):401-408. doi:10.1007/s00277-010-1083-1

55. Reginelli A, Urraro F, Sangiovanni A, et al. Extranodal lymphomas: a pictorial review for $\mathrm{CT}$ and MRI classification. Acta Biomed. 2020;91(8-S):34-42. doi:10.23750/abm.v91i8-S.9971

56. Willemze R, Hodak E, Zinzani PL, Specht L, Ladetto M; ESMO Guidelines Committee. Primary cutaneous lymphomas: ESMO Clinical Practice Guidelines for diagnosis, treatment and follow-up. Ann Oncol. 2018;29(Supp14):iv30-iv40. doi:10.1093/annonc/mdy133

Clinical, Cosmetic and Investigational Dermatology

Publish your work in this journal

Clinical, Cosmetic and Investigational Dermatology is an international, peer-reviewed, open access, online journal that focuses on the latest clinical and experimental research in all aspects of skin disease and cosmetic interventions. This journal is indexed on CAS
57. Ulutin HC, Oztürk B, Ongürü O, Kuzhan O, Arpaci F, Ozet A. Treatment of primary cutaneous B-cell lymphoma with radiotherapy. Radiat Med. 2005;23(4):292-295.

58. Oertel M, Elsayad K, Weishaupt C, Steinbrink K, Eich HT. Deescalated radiotherapy for indolent primary cutaneous B-cell lymphoma. Strahlenther Onkol. 2020;196(2):126-131. doi:10.1007/ s00066-019-01541-7

59. Goyal A, Carter JB, Pashtan I, et al. Very low-dose versus standard dose radiation therapy for indolent primary cutaneous B-cell lymphomas: a retrospective study. $J$ Am Acad Dermatol. 2018;78 (2):408-410. doi:10.1016/j.jaad.2017.07.053

60. Perry A, Vincent BJ, Parker SR. Intralesional corticosteroid therapy for primary cutaneous B-cell lymphoma. Br J Dermatol. 2010;163 (1):223-225. doi:10.1111/j.1365-2133.2010.09798.x

61. Sica A, Vitiello P, Papa A, et al. Use of rituximab in NHL malt type pregnant in $\mathrm{I}^{\circ}$ trimester for two times. Open Med (Wars). 2019;14:757-760. doi:10.1515/med-2019-0087

62. Peñate Y, Hernández-Machín B, Pérez-Méndez LI, et al. Intralesional rituximab in the treatment of indolent primary cutaneous B-cell lymphomas: an epidemiological observational multicentre study. The Spanish working group on cutaneous lymphoma. $\mathrm{Br}$ $J \quad$ Dermatol. 2012;167:174-179. doi:10.1111/j.13652133.2012.10902.x

63. Dreno B, Urosevic-Maiwald M, Kim Y, et al. TG1042 (Adenovirusinterferon- $\gamma$ ) in primary cutaneous B-cell lymphomas: a Phase II clinical trial. PLoS One. 2014;9(2):e83670. doi:10.1371/journal. pone. 0083670

64. Monari P, Farisoglio C, Calzavara Pinton PG. Borrelia Burgdorferi-associated primary cutaneous marginal-zone B-cell lymphoma: a case report. Dermatology. 2007;215(3):229-232. doi: $10.1159 / 000106580$

65. Valencak J, Weihsengruber F, Rappersberger K, et al. Rituximab monotherapy for primary cutaneous B-cell lymphoma: response and follow-up in 16 patients. Ann Oncol. 2009;20(2):326-330. doi:10.1093/annonc/mdn636

66. Leonard JP, Trneny M, Izutsu K, et al. AUGMENT: a phase III study of lenalidomide plus rituximab versus placebo plus rituximab in relapsed or refractory indolent lymphoma. J Clin Oncol. 2019;37 (14):1188-1199. doi:10.1200/JCO.19.00010

67. Sica A, Sagnelli C, Papa A, et al. An anecdotal case report of chronic lymphatic leukemia with del(11q) treated with ibrutinib: artificial nourishment and physical activity program. Int $J$ Environ Res Public Health. 2020;17(6):1929. doi:10.3390/ijerph17061929

68. Visco C, Di Rocco A, Evangelista A, et al. Outcomes in first relapsed-refractory younger patients with mantle cell lymphoma: results from the MANTLE-FIRST study. Leukemia. 2020. doi:10.1038/s41375-020-01013-3

69. Wagner-Johnston ND, Schuster SJ, deVos S, et al. Outcomes of patients with up to 6 years of follow-up from a phase 2 study of idelalisib for relapsed indolent lymphomas. Leuk Lymphoma. 2020;10:1-11. doi:10.1080/10428194.2020.1855344 